\title{
Pulmonary autograft valve explants show typical degeneration
}

\author{
Aart Mookhoek, MSc, ${ }^{\mathrm{a}}$ Emile de Heer, PhD, ${ }^{\mathrm{b}}$ Ad J. J. C. Bogers, MD, PhD, ${ }^{\mathrm{c}}$ \\ Johanna J. M. Takkenberg, MD, $\mathrm{PhD},{ }^{\mathrm{c}}$ and Paul H. Schoof, $\mathrm{MD}, \mathrm{PhD}^{\mathrm{a}}$
}

Objectives: We sought to evaluate the microscopic characteristics of pulmonary autograft valve explants.

\begin{abstract}
Methods: Cell density and thickness of the autograft valve ventricularis were determined and compared with those of normal aortic and pulmonary valves $(n=11)$. Cellular phenotype and extracellular matrix involvement were assessed with immunohistochemistry. Collagen 3-dimensional architecture was studied by means of confocal microscopy.
\end{abstract}

\begin{abstract}
Results: The autograft valve exhibited characteristic thickening of the ventricularis compared with the normal aortic and pulmonary valves (137 vs $77[P=.058]$ vs $37 \mu \mathrm{m}[P=.002]$, respectively). Its cell number was increased compared with those of the normal aortic and pulmonary valves (396 vs $230[P=.02]$ vs 303 $[P=.083]$, respectively). Myofibroblasts and stressed endothelial cells, both of which were present in pulmonary autografts, were absent in control valves. The exclusive presence of matrix metalloproteinase 1 was an additional sign of extracellular matrix turnover. Apoptosis, elastinolysis, cell proliferation, and senescence were not expressed. Dense fibrosis of the autograft ventricularis with relatively well-aligned collagen fibers was observed with confocal microscopy.
\end{abstract}

Conclusions: Fibrous hyperplasia of the ventricularis and cellular and extracellular matrix characteristics of active remodeling were a consistent finding in pulmonary autograft valve explants. The observations suggest a primary valve-related cause to be involved in pulmonary autograft valve failure. (J Thorac Cardiovasc Surg 2010;139:1416-9)

Pulmonary autograft valve regurgitation and root dilatation have emerged as important complications of the Ross procedure at short-term and midterm follow-up. ${ }^{1-3}$ Valve regurgitation has generally been assumed to be secondary to root dilatation, although a primary valve-related cause has never been excluded. In our previous study fibrotic thickening of the autograft ventricularis was identified as a common feature. ${ }^{4}$ Here we systematically studied 11 explanted autografts and 11 control valves to assess and quantify the histopathologic characteristics to support any clinicopathologic correlates.

\section{MATERIALS AND METHODS}

Pulmonary autografts $(n=11)$ were obtained from adults undergoing reoperations for pulmonary autograft failure between 2003 and 2007 in the University Medical Centres of Rotterdam and Leiden, The Netherlands (Table 1). In 10 patients reoperation was indicated because of progressive dilatation of the neoaortic root combined with significant neoaortic valve regurgitation. One patient underwent reoperation because of progressive

\footnotetext{
From the Departments of Cardiothoracic Surgery ${ }^{\mathrm{a}}$ and Pathology, ${ }^{\mathrm{b}}$ Leiden University Medical Center, Leiden, The Netherlands; and the Department of Cardiothoracic Surgery, ${ }^{\mathrm{c}}$ Erasmus University Medical Center, Rotterdam, The Netherlands. Disclosures: None.

Received for publication Nov 21, 2009; revisions received Dec 28, 2009; accepted for publication Jan 10, 2010; available ahead of print April 12, 2010.

Address for reprints: Paul H. Schoof, MD, PhD, Utrecht University Medical Center, Wilhelmina Children's Hospital, Department of Cardiothoracic Surgery, Postbus 85090, 3508 AB Utrecht, The Netherlands (E-mail: p.h.schoof@umcutrecht.nl). $0022-5223 / \$ 36.00$

Copyright (C) 2010 by The American Association for Thoracic Surgery doi:10.1016/j.jtcvs.2010.01.020
}

dilatation of the neoaortic root alone. Age-matched heart valves $(\mathrm{n}=11$; aortic, $\mathrm{n}=5$; pulmonary, $\mathrm{n}=6$ ) obtained from the Heart Valve Bank of the Erasmus MC, Rotterdam, The Netherlands, served as controls.

\section{Sample Staining}

Radial valve sections (4 $\mu \mathrm{m})$ were cut from paraffin-embedded leaflets and mounted on slides. Von Gieson staining was used to visualize elastin and collagen fibers, and Alcian blue staining was used to visualize glycosaminoglycans and nuclei. Sections were photographed with a Zeiss microscope (Zeiss, Oberkochen, Germany) with a Sony DXC 950p full-color 3CCD camera (Sony Corp, Tokyo, Japan) and captured with KS-400 image analysis software, version 3.0 (Zeiss). Von Gieson-stained sections were analyzed with Image J version $1.37 \mathrm{~V}$ to determine the thickness of the ventricularis and total valve thickness. The mean number of nuclei was calculated in Alcian blue-stained sections by counting 4 different sample fields.

Immunohistochemical analysis with 13 different markers was performed to compare autograft valves $(n=11)$ with control valves $(n=11$, Table 2$)$. In general, sections were deparaffinized, followed by antigen retrieval by boiling in $0.1 \mathrm{~mol} / \mathrm{L}$ citrate buffer, $\mathrm{pH}$ 6.0; blocked for endogenous peroxidases; and incubated for 1 hour with the primary antibody. Next, sections were washed and incubated with an Envision horseradish peroxidaseconjugated secondary antibody (DAKO, Glostrup, Denmark). Subsequently, all slides were incubated with diaminobenzidine and analyzed with KS-400 image analysis software to quantify the staining percentage of the ventricularis.

\section{Confocal Microscopy}

Three-dimensional images were made from $20-\mu$ m-thick, paraffinembedded, Sirius red-stained leaflets with an LSM510 confocal microscope with a C-Apochromat 40x/1.2W Corr water immersion objective (Zeiss).

\section{Statistical Methods \\ Continuous data, such as those obtained from histochemical analyses, were compared with the unpaired $t$ test. Discrete data, such as those obtained}


TABLE 1. Clinical data of patients undergoing the Ross procedure and control subjects

\begin{tabular}{lcc}
\hline & Autograft $(\mathbf{n}=\mathbf{1 1})$ & Control $(\mathbf{n}=\mathbf{1 1})$ \\
\hline Age at operation $(\mathrm{y})$ & $24.4(10.5-39.2)$ & NA \\
Age at explantation $(\mathrm{y})$ & $35.8(23.6-47.8)$ & $31.9(19.7-49.7)$ \\
Interval $(\mathrm{y})$ & $11.2(7.3-15.4)$ & NA \\
Male & 9 & 7 \\
Female & 2 & 3 \\
Bicuspid native valves & 7 & 0 \\
\hline
\end{tabular}

$N A$, Not applicable.

from the immunohistochemical analysis of desmin and $\alpha$-smooth muscle actin, were analyzed with Fisher's exact test. Analysis of the correlation between the variables studied and the time to explantation was performed with Pearson's correlation coefficient. All comparative analyses were performed with SPSS 12.0.1 for Windows (SPSS, Inc, Chicago, Ill).

\section{RESULTS}

\section{Histochemical Analysis}

Autograft valves did not differ significantly from normal aortic and pulmonary valves (Figure 1) in their mean total thickness (372 vs 474 [normal aortic valve] and $292 \mu \mathrm{m}$ [normal pulmonary valve]; $P>.2$ and $P=.067$, respectively). Thickness of the ventricularis of the autograft valve $(137 \mu \mathrm{m})$ was significantly greater than that of the normal aortic $(77 \mu \mathrm{m})$ or pulmonary $(37 \mu \mathrm{m})$ valves $(P=.058$ and $P=.002$, respectively). It comprised $36 \%$ of total autograft thickness compared with normal aortic (17\%) and pulmonary $(12 \%)$ valves $(P=.02$ and $P<.001$, respectively). The number of cells per square millimeter in the ventricularis was 396 in autografts compared with numbers seen in normal aortic (230) and pulmonary (303) valves $(P=.02$ and $P=.083$, respectively). Matrix cell morphology was spindle shaped, and cells lining the ventricularis surface appeared large and cubical.

\section{Immunohistochemical Analysis}

The autograft ventricularis was lined by endothelial cells, as identified by means of CD31 staining. Autograft valves showed $\alpha$-smooth muscle actin-positive cells and desminpositive cells in $91 \%$ and $36 \%$ of samples, respectively, compared with $36 \%$ and $0 \%$, respectively, in control samples $(P=.024$ and $P=.035$, respectively). The expression of these markers indicates a myofibroblast-like phenotype of the cells present in the extracellular matrix of the autograft ventricularis. In contrast to controls, the autograft ventricularis stained positive for interleukin 6 , matrix metalloproteinase 1 , and transforming growth factor $\beta$. A very low number of inflammatory cells were present in the ventricularis of both autograft and control samples, as identified by means of CD45 staining. Apoptosis, matrix degradation, cell proliferation, and senescence markers were not expressed. Interestingly, no correlation was present between the variables studied and the time to explantation (data not shown).

\section{Confocal Microscopy}

Collagen fiber density was more pronounced in the ventricularis of autograft valves compared with that seen in normal aortic and pulmonary valves (Figure 2). Moreover, these fibers showed a high degree of geometric organization. Fiber alignment was typically in the radial direction (ie, from wall to rim).

\section{DISCUSSION}

Pulmonary autograft valve explants consistently showed a thickened ventricularis. Its presence along the entire cusp, as well as focal expression of the fibroblast activators transforming growth factor $\beta$ and interleukin 6 , suggest this thickening is the result of a local adaptive response rather than fibrous overgrowth (pannus), as suggested by RabkinAikawa and colleagues, ${ }^{5}$ who observed similar thickening

TABLE 2. Antibodies used in immunohistochemical analysis

\begin{tabular}{|c|c|c|c|c|c|}
\hline Markers & Cellular aspects & Antigen retrieval & Primary antibody & Secondary antibody & Company \\
\hline$\alpha$-SMA & Myofibroblasts & - & $1: 400$ & Mouse & Sigma \\
\hline Active caspase $3^{*}$ & Apoptosis & + & $1: 200$ & Rabbit & Cell Signaling \\
\hline Cathepsin $\mathrm{K}$ & Elastinolysis & + & $1: 1000$ & Rabbit & TNO \\
\hline Cathepsin S & Elastinolysis & + & $1: 1000$ & Rabbit & TNO \\
\hline CD $31 *$ & Endothelium & + & $1: 400$ & Mouse & DAKO \\
\hline CD45 & Inflammatory infiltrate & + & $1: 100$ & Mouse & DAKO \\
\hline Desmin & Myofibroblasts & - & $1: 20$ & Mouse & LUMC \\
\hline IL-6 & Differentiation & + & $1: 500$ & Goat $\ddagger$ & Biogenesis \\
\hline Ki67 & Proliferation & + & $1: 200$ & Mouse & DAKO \\
\hline MMP1 & Collagen breakdown & - & $1: 1000$ & Mouse & Chemicon \\
\hline MMP9 & Collagen breakdown & + & $1: 250$ & Rabbit & TNO \\
\hline $\mathrm{p}^{16 \mathrm{INK} 4 \mathrm{a}_{\dagger}}$ & Senescence & + & $1: 800$ & Mouse & Neomarkers \\
\hline $\mathrm{TGF}-\beta$ & Differentiation & + & $1: 500$ & Rabbit & LUMC \\
\hline
\end{tabular}

$\alpha$-SMA, $\alpha$-Smooth muscle actin; $I L-6$, interleukin $6 ; M M P$, matrix metalloproteinase; $T G F-\beta$, transforming growth factor $\beta$. *Diaminobenzidine enhancement by means of incubation with $\mathrm{Cu}_{2} \mathrm{SO}_{4}$ for 5 minutes. †Antigen retrieval with Tris/ethylenediamine tetraacetic acid. $\ddagger$ Rabbit $\alpha$ goat + streptavidin-biotin-peroxidase complex. 


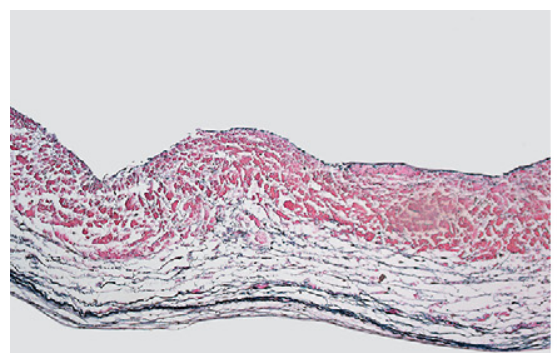

Ao

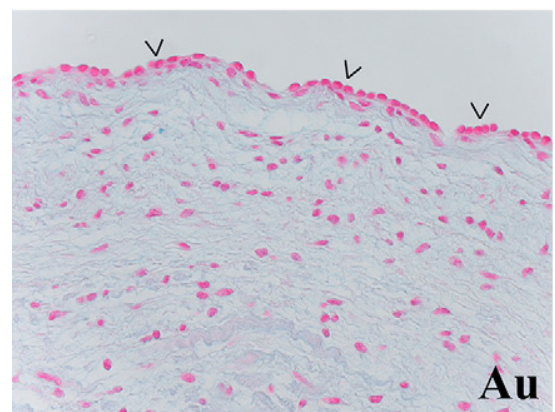

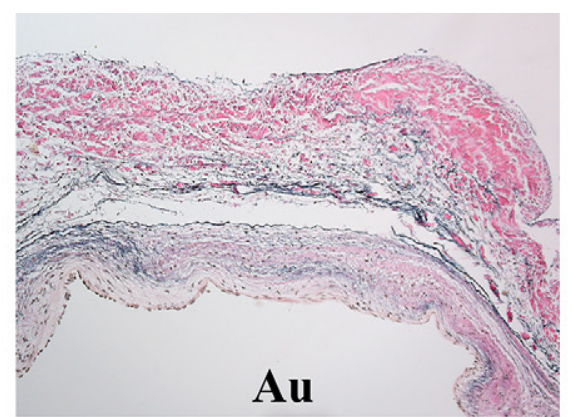
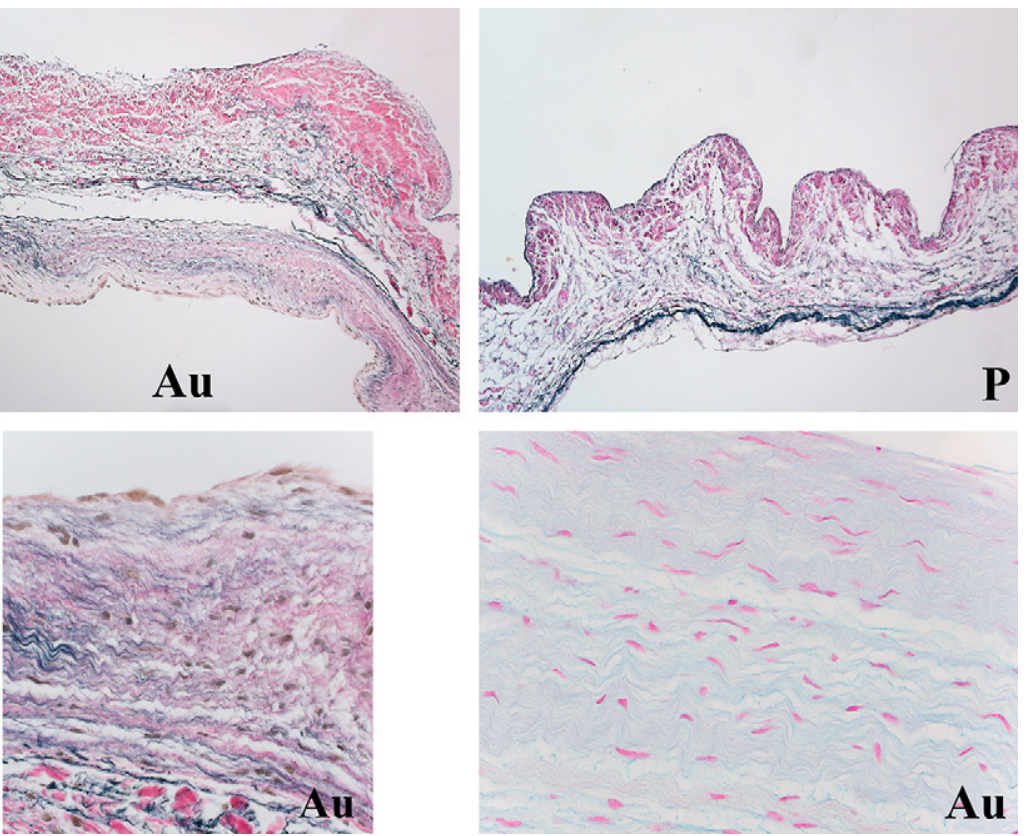

FIGURE 1. Morphologic analysis shows a thickened autograft $(A u)$ ventricularis compared with that seen in normal aortic $(A o)$ and pulmonary $(P)$ valves (upper mid panel, original magnification $135 \times$ ). Detailed photos of the autograft valves show cubical endothelium (lower left, $V$ ), collagen-rich extracellular matrix (lower mid), and high density of spindle-shaped cells (lower right; original magnification, $540 \times$ ).
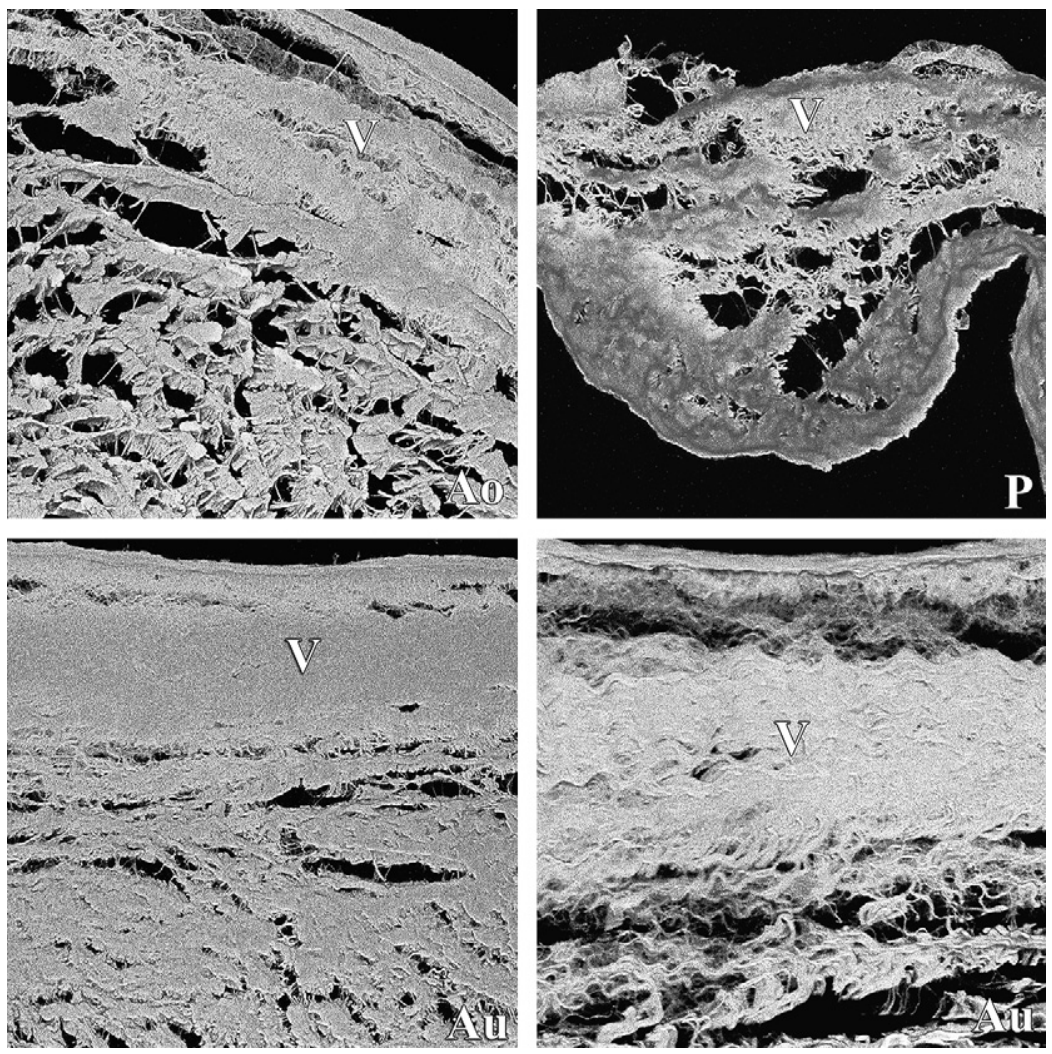

FIGURE 2. Confocal images of valvular collagen structures show an increase in collagen density in pulmonary autograft valves (lower left) compared with that seen in normal aortic and pulmonary valves (upper panels; original magnification, $800 \times$ ). Distinct radial orientation of the collagen fibers is shown at high magnification (lower right; original magnification, 1600×). V, Ventricularis. 
of the pulmonary autograft valve. In addition, we found that collagen fibers were abundant in this area and particularly well aligned, which might implicate that the architectural changes are a result of adaptive remodeling secondary to increased mechanical stress. Interestingly, the remodeling tissue marker matrix metalloproteinase 1 and the presence of numerous myofibroblasts were found in explants that functioned over 10 years in the systemic circulation. It suggests that the adaptation process in the explanted valves did not reach homeostasis. Such an ongoing process of remodeling might eventually be exhausted and lead to degeneration. Interestingly, we found the same changes in an explant from a patient who died of a non-valve-related cause (data not included in this study), ${ }^{4}$ and comparable changes were found in pulmonary autografts of hearts from patients who required transplantation after the Ross procedure. ${ }^{5}$ This suggests a common mode of adaptation that might occur to some extent in all autograft valves, and therefore the relation with clinical valve failure is uncertain. However, when speculating on a cause of valve failure, the presence of a thick fibrous layer is likely to negatively influence the delicate microdynamics of the valve, particularly its radial extensibility. Obviously, biaxial stress testing should be performed to substantiate this. We believe that the observed remodeled ventricularis is the result of beneficial adaptation but might eventually play a role in failure of the pulmonary autograft valve.

\section{CONCLUSION}

Fibrous hyperplasia of the ventricularis is a consistent finding in pulmonary autograft valve explants. Its cellular and extracellular matrix characteristics at explantation suggest it to be the result of sustained remodeling. The architec- tural changes can cause failure of the pulmonary autograft valve in the long-term.

\section{Limitations}

The valves used in this study were all acquired from failing autografts. This impedes the extrapolation of our results to autograft valves in general. Valves from failing autografts should ideally have been compared with valves from nonfailing autografts to enable such an extrapolation.

\section{Future Perspectives}

It would be useful to perform a similar study with explanted valves from patients who underwent a classic Ross procedure by using the subcoronary implantation technique or from roots supported with Dacron. Because these autografts are unaffected by progressive root dilatation, the valve's intrinsic tendency for failure can be more accurately studied. Detailed characterization of the collagen fibers in the ventricularis could provide additional information on the structure and quality of collagen.

\section{References}

1. Luciani GB, Mazzucco A. Aortic root disease after the Ross procedure. Curr Opin Cardiol. 2006;21:555-60.

2. Klieverik LM, Takkenberg JJ, Bekkers JA, Roos-Hesselink JW, Witsenburg M Bogers AJ. The Ross operation: a Trojan horse? Eur Heart J. 2007;28:1993-2000.

3. Pasquali SK, Shera D, Wernovsky G, Cohen MS, Tabbutt S, Nicolson S, et al. Midterm outcomes and predictors of reintervention after the Ross procedure in infants, children, and young adults. J Thorac Cardiovasc Surg. 2007;133:893-9.

4. Schoof PH, Takkenberg JJ, van Suylen RJ, Zondervan PE, Hazekamp MG, Dion RA, et al. Degeneration of the pulmonary autograft: an explant study. J Thorac Cardiovasc Surg. 2006;132:1426-32.

5. Rabkin-Aikawa E, Aikawa M, Farber M, Kratz JR, Garcia-Cardena G, Kouchoukos NT, et al. Clinical pulmonary autograft valves: pathologic evidence of adaptive remodeling in the aortic site. J Thorac Cardiovasc Surg. 2004;128: 552-61. 